Proceedings of the Eleventh Annual Meeting of the Japan Society of Histochemistry and Cytochemistry in Tokyo, November 9 and 10, 1970.

President : Dr. Yoshihiro Hamasima

Vice-President : Dr. Kenjiro Yasuda

- GENERAL SESSION-

\title{
Histochemical Studies on Steroid-3 $\beta$-ol Dehydrogenase in Some Transplantable Tumors of Mice
}

Takehiko Mryashita, Akitsugu OJima, Kuniyasu Shimokawa, Matsue Mizushima and Hidemichi Yamauchi

Department of Pathology, Gifu University School of Medicine, Gifu

It is generally accepted that transplantable tumors increase their growth rate and decrease their proper function along with serial transplantation. However, is it always true? In order to examine this problem, activity of steroid- $3 \beta$-ol dehydrogenase (Wattenberg's method) was studied on Gardner's 107 testicular interstitial cell tumors (ICT), pulmonary tumors (PT) and liver cell tumors (LT), both originated in our department, and on Gardner's 519 osteosarcomas (OS). Dehydroepiandrosterone (DHA) or pregnenolone with or without iodacetic acid (inhibitor) were used as substrates.

Estrogen producing ICT consistently showed moderately positive reaction even at the time when more than 50 transplantation generations were passed. It was very interesting that 3 out of 29 PT examined showed moderately positive reaction just like ICT, because PT showed hyperestrogenism in their hosts in some period of serial transplantation when tumors became less differentiated morphologically. Three out of $15 \mathrm{LT}$ were also positive moderately; however, the authors presume that it depends on endogenous dehydrogenase, because they were positive even when without substrate. None of OS showed moderately positive reaction. Generally speaking when DHA was used, the reaction was stronger than when pregnenolone was used in this study.

\section{The Study of the Experimental Hypertension}

- Histochemical observations of the regenerated adrenals and plasma corticosterone concentrations from hypertensive rats-

Teruhiro Nakada, Goichi Momose and Toyohiko Yoshida

Department of Urology, School of Medicine, Chiba University, Chiba

It has been speculated that excess of some adrenocortical steroids could be involved in the pathogenesis of the adrenal regeneration hypertension. However, 
as far as we know, numerous attempts failed to indicate such steroid which would be expected to rise blood pressure.

In immature male rats treated with $1 \%$ sodium chloride, uninephrectomy besides bilateral adrenal enucleation was performed in one group, and bilateral adrenal enucleations without renal removals were undergone in another group. After 30 days, the severity of hypertension increased up to $156 \pm 8 \mathrm{~mm} \mathrm{Hg}$ (mean \pm S.E.) in the former group, however the latter remained normotensive. Enhanced activity of $3 \beta$ hydroxysteroid dehydrogenase and glucose-6-phosphate dehydrogenase was remarkably observed in the regenerated adrenals of both groups.

The experiments described here have been carried out in an attempt to elucidate the possible role of corticosterone secreted from regenerating adrenocortical tissue in the genesis of hypertension. The concentrations of plasma corticosterone in the experimental rats were measured by van der Vies method. But as for the corticosterone concentrations, there was no difference between the plasma of hypertensive rats and that of normotensive rats.

\title{
Some Histochemical Studies on the Adrenal Gland
}

\author{
Ryo TABeI \\ Department of Pathology, Faculty of Medicine \\ Kyoto University, Kyoto
}

1) Administration of somatotropin plus $17 \alpha$-estradiol to mice (A/Jax, C57BL) and Wistar rats for two months revealed the following results in their adrenal medulla: In mice, activities of ACPase, Esterase and MAO showed no significant difference or were slightly decreased in treated animals compared to the controls. In rats, hypertrophic tendency was observed by about $20 \%$ in weight compared to those of the nontreated.

2) When Wistar rats were given nicotine ( $4 \mathrm{mg} / \mathrm{rat}$ ) daily, the adrenals also showed an increase in weight by about $20 \%$. MAO and AChE activities were markedly increased in the treated adrenal medulla compared to the control.

3) In the adrenal cortex of the hormone treated rats, a marked increase in G-6-PD activity and hypertrophic tendency which is suggestive of augmented steroidgenesis were observed.

4) When the same hormone treatment was applied to the spontaneously hypertensive rat, many small vesicles in the cytoplasma of the medullary cells, while these were absent in the control were observed.

The above results seem to suggest that the hypertrophy of the adrenal medulla produced by the hormone treatment has no connection with the augmented catecholamine synthesis and the finding observed in the medulla of the spontaneously hypertensive rat may not mean the hyperactive state. 


\title{
Consideration of Decalcification by EDTA and the Fixation to the Skeletal Tissue in Enzyme Histochemistry.
}

\author{
Minoru SAKURAI \\ Dept. of Orthoped. Surg. \\ Tohoku Univ. Sch. of Med., Sendai
}

EDTA solution in $5 \%$ is known to be available for decalcification preserving alkaline and acid phosphatase activity after fixation by cold formalin or acetone. An addition of neutral detergent in $1 \%$ to above solution can facilitate the process of decalcification by a mechanism of penetration through fatty tissue which may pupress the flow of solution. When a morphology and diffusion of enzyme is compared in formalin and acetone fixation, the former was found to be rather satisfactory.

When decalcification is required for a fixationlabile enzyme which associates with bone, cold decalcification solution consisting of 5\% EDTA, 4\% sodium sulfate and $1 \%$ detergent is first applied to a specimen, agitated by magnetic stirrer in a refrigerator for few days. Then the tissue is quenched and sectioned in a cryostat, then incubated for enzymatic reaction. Several kind of enzyme as phosphorylase, lactate dehydrogenase, cytochrome oxidase could be significantly stained but scarcely succinate dehydrogenase. Sodium sulfate added to a solution is able to so supress a diffusion of enzyme, that localization of enzyme is satisfactorily detected.

\section{Histochemical Study of Lysosomal Enzymes in the Inner Ear.}

Tetsuo IsHII

The department of otolaryngology, The Tokyo Hospital of Japan Monopoly Corporation, Tokyo

Acid phosphatase, $\beta$-glucuronidase and $\mathrm{N}$-acetyl- $\beta$-glucosaminidase activities were demonstrated using naphthol AS-BI salts previously reported by Barka and Anderson (1962), Hayashi, Nakajima and Fishman (1964) and Hayashi (1965), respectively. The temporal bones of guinea pigs were decalicified with $10 \%$ EDTA solution buffered by $0.2 M$ phosphate, $\mathrm{pH} 7.4$. The sites of these 3 enzyme activities were essentially the same. Intense activities were found in the supranuclear portions of the outer and inner auditory hair cells and the vestibular hair cells. The stria vascularis showed intense, diffuse activities throughout the tissues. The tissue behind the spiral prominence and the external sulcus presented strong activities. The epithelia of the limbus spiralis showed the histochemical reactions. These areas were known to have secretory and/or absorptive function by histologists. The free floating cells and the epithelium of the endolympahatic sac showed intense lysosomal enzyme activities. The free floating cells in the sac were supposed to have phagocytic function, whereas the epithelia of the endolymphatic sac were known to deal with absorption of the endolymph. All these localizations were found to correlate well with the presence of the lysosomes or lysosome-like granules reported by electron microscopists. 


\title{
Mechanism of Formazan Formation in Hair Gells of Corti's Organ by Means of Intracochlear Vital Incubation of Stianing Solution Containing Nitroblue Tetrazolium for Demonstration of Dehydrogenases in the TGA Gycle and Electron Transfer System.
}

\author{
Masatoyo Akiyoshi and Kiichi Sato \\ Department of Pathology, Institute for the Deaf, \\ Tokyo Medical and Dental University, Tokyo
}

In the succinic tetrazolium reductase reaction(STRR) coenzyme $\mathrm{Q}(\mathrm{Go} Q)$ plays an important role of intermediate electron carrier(Horwitz et al. 1967). On the other hand in the energy-linked electron transfer reaction, GoQ is carrying out an important function as a collecting pool for hydrogen from various dehydrogenases (Lingenberg and Kröger. 1967). The present authers made following experiments to elucidate an influence of nonspecific enzymatic reduction on the formazan formation within the hair cells in various tetrazolium reductase reactions performed in vivo. The intracochlear incubation of the staining solution containing various kinds of substrates and nitro blue tetrazolium(NBT) was carried out for demonstration of the in vivo activity of succinic dehydrogenase, NAD-linked malic dehydrogenase, NAD-linked isocitric dehydrogenase, NADP-linked isocitric dehydrogenase, NADH dehydrogenase and NADPH dehydrogenase within the hair cells is 6 living guinea pigs under general anesthesia with nembutal. On the other hand, the intracochlear incubation of the staining solution without substrate was made for demonstration of nonspecific enzymatic reduction by CoQ with hydrogens transfered from various hydrogenases in 6 living guinea pigs under general anesthesia and in 6 ones at 5, 10 and 30 minutes after decapitation. In addition, enzyme inhibition by malonic acid and heating was performed to detect nonemzymatic reaction and STRR was made after the extraction and reconstitution of CoQ on fresh cryostat sections of the rat liver according to Horwitz et al.

The present experiments suggest that in the vivo reduction of NBT the hydrogens originate from various dehydrogenases other than the definite one. This nonspecific emzymatic reduction was of milder degree in vivo and became decreased after death.

\section{Acid Phosphatase Activity in the Ameloblast and the Osteoclast of Young Rat}

\author{
Yoshiaki Kurahashi and Syusaku Yoshiki \\ Department of Pathology, Tokyo Dental College, Tokyo
}

Acid phosphatase activity in the ameloblasts and osteoclasts was investigated histochemically by means of both the azo-dye and the metal salt techniques, using naphthol AS-MX phosphate and $\beta$-glycerophosphate as substrate respectively.

Acid phosphatase in the formative ameloblasts was demonstrated by the both techniques and the activity was inhibited by sodium fluoride and sodium molybdate. 
The enzyme of the ameloblast in the stage of enamel maturation was demonstrated at the Golgi region and at the striated border when the azo-dye technique was applied. By means of the metal salt technique, however, the enzyme activity was not demonstrated at the striated border. The enzyme activity at the Golgi region was inhibited by the inhibitors, but that at the striated border was not inhibited.

Acid phosphatase activity in the osteoclast was demonstrated by means of both the azo-dye and the metal salt techniques. The activity demonstrated by means of the latter technique was inhibited completely by sodium fluoride, and sodium molybdate while all of the activity by means of the former technique was not inhibited by sodium fluoride.

\section{A Study on an Histochemical Glassification of the Gastric Cancer.}

Takao Kawashima, Takuro Ogata, Kunio Okazima and Sanae Tanaka. Dept. of Surg., Okayama University Medical School, Okayama

An enzyme histochemical classification was applied to gastric cancers which were surgically removed in our surgical survice within a period of 5 years from 1960 to 1965. This result has been reported partially in Gann 61, 299 and proceeding of the Japanese Cancer Association 29th Annual Meeting. Histochemical reactions of enzymes used in this classification were G-6-PDH, SDH, esterase and aminopeptidase. These enzymatic stains are strikingly reactive for each specific epithelial cell of the human stomach, but these staining intensities are affected by nercrosis, degeneration, inflammation and wander-cell infiltration. Therefore, biopsy of the cancer should be as large as possible in size, the staining intensity should not be estimated at the necrosis or degeneration in the cancerous mass and also influences of the inflammation and wander-cells should be omitted when the staining intensity is evaluated.

Five-year survival rate for the patients who had curative gastrectomy for type 3 cancer was worest of $20 \%$, while the best was $75 \%$ of type 5 . 5-year survival of the other types were $40 \%$ to $62.5 \%$. Those of patients treated by non-curative operations are all zero except those of types 3 and 2, which were $20 \%$ and $14.3 \%$ respectively. Besides, correlative relation between this classification and mode of the growth, and moreover the histological findings were discussed.

\section{Histochemical Study of the Testis and the Prostatic Gland}

Yoshio Aso, Yoshinobu Hoshino and Isao Murahashi

The Department of Urology, Faculty of Medicine, the University of Tokyo, Tokyo

The testis and the prostatic gland were studied histochemically in adult male rats.

The rats were divided into the following four groups. 
1) the control groups.

2) the group receiving gonadotropin.(H G G) 50 I. U./day.

3) the group receiving testosterone $10 \mathrm{mg} /$ day.

4) the group receiving estrogen. $2.5 \mathrm{mg} /$ day,

Changes of the activities of acid phosphatase, alkaline phosphatase, leucine aminopeptidase, succinate dehydrogenase, glucose-6-phosphate dehydrogenase and $3 \beta$-hydroxysteroid dehydrogenase were estimated.

In control rats these enzyme activities excluding $3 \beta$-hydroxysteroid dehydrogenase were observed on glandular cells in the prostatic glands. And in the testis these enzyme activities were mainly on the interstitial cells.

The prostatic gland showed hypertrophy and the enzyme activities in the testis and the prostatic gland were increased by gonadotropin.

By testosterone marked hypertrophy and increased enzyme activities were seen in the prostatic gland but no remarkable changes of the enzyme activities were observed in the testis.

By estrogen the prostatic gland showed atrophy and the enzyme activities were decreased but were not completely absent in the atrophic glandular cells. Slight decrease of the enzyme activities in the testis was observed.

\title{
The Enzyme Histochemical Observations of Dermatopathic Lymphadenitis:
}

\author{
Natsue Shimizu \\ Department of Dermatology, Keio University School of Medicine \\ Keiichi Watanabe and Shigeo Masubughi \\ Department of Pathology, Keio University School of Medicine, Tokyo
}

In our previous enzyme histochemical study on 33 randomly collected lymph nodes (gastric, cervical and inguinal), it was proved that the immunological reactivitity of lymph nodes would be well substantiated by the alkaline phosphatase $(\mathrm{AlP})$ activity of reticulum cell networks and $\beta$-glucuronidase $(\boldsymbol{\beta}-\mathrm{G})$ positive lymphocytes in the paracortical areas and the numbers of $\beta-G$ positive plasma cells in the medullary cords.

In the present report, the inguinal lymph nodes (9 cases) and skin (4 cases) from the patients of exfoliative dermatitis (E.D.), which is known as the most representative skin disease causing in "dermatopathic lymphadenitis", were enzyme histochemically investigated. The lymph nodes (12 cases) of SLE patients, whose serum IgG titer was marked very high, were also histochemically observed and their enzymorphologic patterns were compared with those of E.D.

In the case of E.D., AlP in the reticular networks was obviously decreased, while the lymph nodes of SLE showed marked increase of AlP and irregular thickening of the networks.

Marked decrease of $\beta-G$ positive lymphocytes and $\beta-G$ in the post capillary venules in the paracortical areas were evidenced in E.D. lymph nodes showing a clear contrast to those changes in SLE. On the other hand, $\beta-G$ positive lympho- 
cytes were perivascularly infiltrating in the skin of E.E. patients, while the infiltrates were mainly composed of $\beta-\mathrm{G}$ positive plasma cells in the SLE skin. Sections were taken from the tuberculin reaction positive lesion of the skin and stained for $\beta-G$ and the infiltrating lymphocytes showed $\beta-G$ activity. The possibility of the delayed hypersensitivity being attributable to E.D. is discussed.

\title{
Effects of Glutaraldehyde of Formaldehyde Fixation on Mouse and Rat Hepatic Glucose 6-Phosphatase Activity
}

\author{
Shinsuke KANAMURA
}

\section{Department of Cytochemistry, Chest Disease Research Institute Kyoto University, Kyoto}

The difference in resistance to aldehyde fixation between mouse and rat hepatic glucose 6-phosphatase activity was studied by fixing cryostat sections of liver for various periods of time in $3.8 \%$ neutral glutaraldehyde or $4 \%$ neutral formaldehyde at $3.5 \sim 4^{\circ} \mathrm{C}$. An apparent difference was found in resistance to fixation between mouse and rat enzyme, and the enzyme activity survived in mice twice to three times longer than in rats during fixation. Biochemical assays of the enzyme activity showed that mouse liver showed only a slightly higher, although significant level of the enzyme activity than rat liver. Further, although fasted rat liver showed a significantly higher level of the enzyme activity than mouse liver, the histochemical reaction in fasted rat liver was abolished by fixation for shorter or about same periods of time than in mouse liver. These results suggests that the difference in resistance to glutaraldehyde or formaldehyde fixation between mouse and rat hepatic G-6-Pase activity is not due to any difference in the level of the enzyme activity between mouse and rat liver, but to the difference in the properties of the enzyme itself between mouse and rat liver.

\section{Ultrastructural Demonstration of Hepatic Glucose 6-Phosphatase}

\author{
Shinsuke KanAmura
}

\section{Department of Cytochemistry, Chest Disease Research Institute, Kyoto University, Kyoto}

Ultrastructural localization of hepatic glucose 6-phosphatase was studied in fresh frozen sections followed by fixation in glutaraldehyde. Blocks of tissue from mouse and rat liver were frozen on dry ice. About $20 \mu$ cryostat sections were placed on slides without adhesion, fixed at $3.5 \sim 4^{\circ} \mathrm{C}$ in neutral $3.8 \%$ glutaraldehyde containing $0.25 M$ sucrose and $0.05 M$ cacodylate, washed in $0.25 M$ sucrose at $4^{\circ} \mathrm{C}$ for $1 \mathrm{hr}$, incubated in Wachstein-Meisel medium for $15 \mathrm{~min}$ at room temperature, washed in water, immersed in dilute yellow ammonium sulfide, then washed and postfixed in $1 \% \mathrm{OsO}_{4}$. The sections were dehydrated and immersed in Epon-propylene oxide mixture, then the sections were carefully stripped from slides and embedded in Epon. Reaction product was seen in nuclear envelope, rough and 
smooth endoplasmic reticulum. Mitochondria, lysosome, microbody or Golgi body contained no reaction product. The preservation of fine structure was satisfactory, although slight dilatation of cisternae of endoplasmic reticulum. This method is thought to be useful for ultrastructural demonstration of hepatic glucose 6-phosphatase activity of very small animals and embryos in which perfusion is difficult to perform.

\title{
Alkaline Phosphatase Activity in the Interstitial Cells and Decidual Cells of the Pregnant Rat Uteri: An Electron Microscopic Cytochemical Observation
}

\author{
Masahiko SAga, Masaru Anbe*, Hiroshi Suzuki and Keiichi Watanabe \\ The Department of Pathology, School of Medicine, Keio University \\ and * The Department of AnatomyII, Toho Medical School, Tokyo
}

The alkaline phosphatase (AIP) activity of the cells involved in decidualization in Wistar-Imamichi rat uterus was enzyme cytochemically observed at both light and electrone microscopic levels.

$\mathrm{Up}$ to $\mathrm{L}_{3}$ (3 days after mating), no visible AlP activity was demonstrated in the interstititum or in the fibroblastic interstitial cells of the uterus. The first apperance of AlP in these cells was recognized at the $\mathrm{L}_{4}$ stage, and then the activity gradually increased until reaching its maximum at the $\mathrm{L}_{8}$ stage, when the decidual tissue was morphologically best developed. So that, the efforts to make the cytochemical observation was concentrated on the uteri of $\mathrm{L}_{4}$ to $\mathrm{L}_{8}$ rats, and step-wise changes of the AlP cytochemical localization patterns of the proliferating fibroblastic interstitial cells were noted during the process of decidualization as follows: $\mathrm{L}_{4}$ :- AlP was localized in the membranes of the elongated mitochondria. $\mathrm{L}_{5}:-$ The increased mitochondrial activity and the appearance of the faint AlP activity in the cytomembranes. Moderately intense AlP was also present along the collagenous fibers and the surrounding mucoprotein ground substance. $\mathrm{L}_{6}$ :- The intense AlP activity on the cytomembrane of the swollen interstitial cells which were closely packed and in the condensed interstitial ground substance. $L_{7} \& L_{8}$ :- The very intense AlP activity exclusively in the cytomembranes tightly connected with the adjacent cells by numerous tight junctions. These AlP positive membranes were often forming intercellular canalicular structures which resembled the bile canalicult in the liver.-Typical decidual cells.

Thus, the process of the transformation from the fibroblastic interstitial cells to the typical decidual cells, which were endowed with secreting epithelial characters, were clearly and definitely demonstrated by the cytochemical observation on AlP in the pregnant rat uteri. 


\title{
A Histochemical Study on Alkaline Phosphatase in Germ Free Mice
}

\author{
Rikio Niki and Keichi Watanabe \\ Department of Pathology, School of Medicine, Keio University, Tokyo \\ Kazuyoshi Maejima and Yoshihiro, Krughi \\ Department of Animal Pathology, the Institute \\ of Medical Science, the University of Tokyo, Tokyo
}

In our previous histochemical study, we reported that the alkaline phosphatase (AlP) activities in the liver (bile canaliculi), spleen (perifollicular region), intestine (brush border of the epithelial cells) and lymph node (medullary cord) were extremely elevated in the germ-free mice of ICR strain compared with those of conventional mice.

In the present report, histochemical observations were made on AlP activities in the livers and the spleens of the following ICR mice: I. Germ-free 2. Germ-free mice monocontaminated (gnotobiotes) by or immunized with (a) a single strain of enteric bacteriae (cf E. coli), (b) Staphylococcus aureus (or other purulent bacteriae) and (C) chrome vaccine of salmonella enteritidis. 3. conventional ICR mice with (a) no special treatment or (b) a sufficient streptomycin administration to get the enteric bacteria free state. The serum AlP titer of these groups of mice was also measured.

Eminently elevated AlP activities in the liver and spleen of Group"1"(Germ-free) mice were sharply decreased by the contamination of some enteric bacteria ("2 (a) ") but not by the contamination of staphylococci (" 2 (b)") or immunization with the chrome vaccine ("2 (C)").

Although the bile canaliculi (liver) and perifollicular regions (spleen) of the conventional mice ("3 (a)") showed almost no AlP activity, the intense AlP activity in the capillary endothelia remained unaltered with "the conventionalization" of germ-free mice. In the enteric bacteria-free mice, the AlP activities in the bile canaliculi and peripheral region of the splenic follicles were moderately recovered.

Changes of the serum AlP titer among these different experimental groups of mice were quite similar to those of histochemical AlP activities in the livers and spleens.

The critical decrease of the liver, spleen and serum AlP might be owing mainly to the contamination of the enteric bacteria.

\section{The Changes of Non-specific Alkaline Phosphatase Activity in the Small Intestine of Developing Rat}

\author{
Kazuyuki ONo
}

\section{Dept. of Anatomy, Iwate Medical College, Morioka}

Non-specific alkaline phosphatase activity was light and electron microscopically investigated in the small intestine of rats from birth to 30 days of age. Glutaraldehyde-fixed frozen sections were incubated for 15 minutes in a mixture of 1-naphthyl 
phosphate and hexazotized pararosanilie.

From the day of birth until the 15 th, day alkaline phosphatase activities of duodenal epithelium were observed only on membranes covering microvilli. And then, on the 23rd and 25th day, phosphatase activities were observed in the same sites as those in full grown rat, i.e. on the microvilli, the lateral cell membranes and Golgi apparatus. In the ileal epithelium, the alkaline phosphatase was localized on the microvilli and the cytoplasmic smooth membrane system until the 20th day after birth. On the 23rd day, however, the activities were no longer seen. In contrast to these changes, the localization of alkaline phosphatase in the jejunum showed no change with age: The reaction products, azo dyes, were situated only on the microvillus membrane of the absorptive cells.

\title{
Electron Microscopic Enzyme Histochemistry on Plasma Membrane Fraction Isolated from Rat Liver II. Effects of Acetone upon the Activities of ATPase and 5'-Nucleotidase of Isolated Plasma Membranes
}

\author{
Kin-ichi OHKAwA \\ Department of Cytochemistry, The Chest Disease Research Institute, \\ Kyoto University, Kyoto
}

Plasma membranes were isolated from rat liver by sucrose density gradient centrifugation after homogenization in $1 \mathrm{mM}$ sodium bicarbonate solution. The isolated hepatic plasma membranes were treated with either absolute acetone or $10 \%$ water in acetone for 10 minutes at $25^{\circ} \mathrm{C}$ or $2^{\circ} \mathrm{C}$ prior to the incubation in the media for ATPase and 5'-nucleotidase (prepared according to Wachstein and Meisel). The treatment of the isolated plasma membranes with absolute acetone did not give any specifically inhibitory effects upon the activities of the enzymes. Ten per cent water in acetone, however, inhibited the activity of ATPase completely. The activity of 5'-nucleotidase was not significantly influenced by $10 \%$ water in acetone. The plasma membranes treated with $10 \%$ water in acetone at $2^{\circ} \mathrm{C}$ gave the positive reaction for ATPase activity. As previously reported the activities of both enzymes locate asymmetrically at the outer reaflets of the membrane element lining the bile canaliculi and also at the cytoplasmic surfaces of the tight junctions.

The activity of ATPase both at bile canaliculi and tight junctions showed the same behavior to the treatments with absolute acetone or $10 \%$ water in acetone as stated above. The activity of 5'-nucleotidase at both sites had the different response to the treatments from that of ATPase.

These electron microscopic findings are in good agreement with the previous light microscopic observations.

The differential effects of absolute acetone and 10\% water in acetone upon ATPase and 5'-nucleotidase are explained on the basis of the phospholipid dependency of ATPase of hepatir plasma membranes. 


\title{
Phosphatases in the Pregnant Rat Uterus in the Middle Stage of Gestation
}

\author{
Hiroshi Suzuki, Keiichi Watanabe and Masahiko SAGA* \\ The Department of Pathology and * the Department of Obstetrics and Gynecology, \\ School of Medicine, Keio University, Tokyo
}

The alkaline phosphatase(AlP) and 5'-nucleotidase (5'-Ndase) activities of rat uterus in the middle stage of gestation ('L8'-8 days after mating -, 'L9', 'L10' and ' $L 11$ ') were histochemically investigated. As the experimental animals, pregnant Wistar-Imamichi rats were used. Two different histochemical methods, modified Tranzer's ( $\mathrm{pH}$ 9.4) and Wachstein-Meisel's ( $\mathrm{pH} 7.4$ ), were employed for the demonstration of either AlP or 5'-Ndase with the following substrates: $\beta$-glycer ophosphate, 3'-AMP and three other organic phosphates for AlP; 5'-AMP, -UMP, -GMP and -IMP for 5'-Ndase.

In the uterus of 'Lll' rat, the intence AlP activity was demonstrated in the outer fibrous tissue zone lying just beneath the muscular layers, the newly formed trophoblastic tissues and rather weak activity in the anti-mesometrial but not at all in the mesometrial decidua. Differing from AlP, the intense 5'-Ndase activity was localized not only in the antimesometrial but also more prominently in the mesometrial decidua, besides the moderately intense activity in the newly formed trophoblastic tissues and the outer fibrous tissue zone and the further less intense activity in the muscular layers. Although the identical localization pattern was obtained in the 5'-Ndase reaction performed at two different $\mathrm{pHs}, 9.4$-modified Tranzer's method and 7.4-modified Wachstein-Meisel's method, the stronger and more constant reaction was obtained with the former method in a shorter incubation. However, the more critical intervention of AlP might be expected in the enzymatic cleavage of the substrate (5'-nucleotide) at the alkaline $\mathrm{pH}$ than at the neutral one. Thus, several 1-amino acids (1-phenyl alanine, 1-histidine etc.) known as the inhibitor of AlP were added to the reaction media for both AlP and 5'-Ndase at $\mathrm{pH}$ 9.4. The reactions with substrate phosphates other than 5'-nucleotides were almost perfectly inhibitted by the addition of those amino acids, while the inhibition was only noted in the outer fibrous tissue zone and the trophoblastic tissues in the reaction with 5'-nucleotides as substrate. In the case of the latter (5'-Ndase), the intense reaction in the mesometrial unaltered. Therefore, the enzyme reaction demonstrated in the last two sites would quite possibly be the very specific one for 5'nucleotidase.

By adding these 1 -amino acids to the reaction media, the difference of the daily dramatic changes of the localization patterns between AlP and 5'-Ndase in the rat uteri in the middle stage of gestation was clearly demonstrated.

\section{Quantitative Histochemistry of Squamous Cell Carcinoma, Paget Disease and Normal Epidermis.}

Hideo Uno and Masaoki Harada

2nd Institute of Pathology, School of Medicine, Yokohama University, Yokohama

Fluorometric micro enzyme assay was applied to compare with the activities of 
glycolytic enzymes among normal human epidermal tissue, tissues of Paget disease and squamous cell carcinoma. The tissues of squmaous cell carcinoma were divided keratinized layer and basal cell layer. The activities of hexokinase and glucose-6-phosphate dehydrogenase were three times higher in basal layer of squamous cell carcinoma and Paget disease than those of normal epidermal tissue. The keratinized layer of squamous cell carcinoma showed the lowest activities. The activities of both enzymes in normal epidermal tissue were approximately 1 moles per Kg. dry weight per hour. Lactic dehydrogenase was twice much higher activity in those neoplastic epidermal tissue thar normal. Activity of lactic dehydrogenase of normal epidermis showed 25 moles per $\mathrm{Kg}$. dry weight per hour. Considerable differences of the activity between neoplastic and normal epidermal tissue were found in isocitric dehydrogenase. Neoplastic tissue showed more than ten times activity complared to norma epidermis. The activity of isocitric dehydrogenase of basal layer of squamous cell carcinoma and Paget disease measured approximately 20 moles per $\mathrm{Kg}$. dry weight per hour.

Those results suggested that neoplastic epidermal cells were actively utilizing glucose into glycolysis and hexose-monophosphate pathway. The most striking change was found in the activity of enzyme related to TCA cycle, isocitric dehydrogenase.

\title{
Quantitative Histochemical Studies of the Renal Tubules of Experimentally Induced Osmotic Nephrosis
}

\author{
Masaoki Harada and Hideo Uno \\ 2nd Institute of Pathology, School of Medicine, Yokohama University, Yokohama
}

Remarkable hydropic degeneration of the renal tubular epithelium of the proximal convoluted tubules induced with transfusion containing low molecular dextran and some plasma expander is conventionally called osmotic nephrosis. We have succeeded in inducing an experimental osmotic nephrosis on rabbit with intravenous injection of $20 \%$ sucrose, $8 \mathrm{gm}$ per $\mathrm{kg}$. body weight. The proximal convoluted tubules, tubules of pars recta and collecting tubules were dissected from frozen dried thin sections of normal and nephrotic rabbit kidney. The activities of the enzymes related to carbohydrate metabolism were measured by Lowry's fluorometric micro enzyme assay. The activity of Na-K ATPase was also assayed by the method of Bonting and Nakao. The activities of hexokinase and glucose-6-phosphate dehydrogenase among three different regions of the nephron of both normal and nephrotic kindeys were essentially unchanged. The activity of lactic dehydrogenase was twice much high in the tubular epithelium of pars recta compared with normal. increased enzyme activities on nephrotic tubules were found in those of isocitrate dehydrogenase, glutamic-alanine- and glutamic-aspartate-transaminase especially in the region of pars recta and collecting tubules. The activity of Na-K ATPase was slightly decreased on nephrotic tubules of pars recta. Conclusively, remarkable hydropic degeneration of the epithelium of the proximal convoluted tubules of osmotic nephrosis was not suggested as fatal destructive change of the cells on the base of enzyme preservation. Functional reduction of active transport of the 
renal tubular epithelium may be represented as dicreased activity of Na-K ATPase on nephrotic kidney.

Enzymatic activity of rabbit renal tubules

\begin{tabular}{|c|c|c|c|c|}
\hline & & $\begin{array}{l}\text { Proximal } \\
\text { cnovolution }\end{array}$ & Pars recta & $\begin{array}{l}\text { Collecting } \\
\text { tubules }\end{array}$ \\
\hline $\mathrm{Na}-\mathrm{K}$ ATPase & $\begin{array}{l}\text { normal } \\
\text { nephrotic }\end{array}$ & $\begin{array}{l}1.82 \\
1.75\end{array}$ & $\begin{array}{l}1.83 \\
1.22\end{array}$ & $\begin{array}{l}0.43 \\
0.49\end{array}$ \\
\hline Hexokinase & $\begin{array}{l}\text { normal } \\
\text { nephrotic }\end{array}$ & $\begin{array}{l}1.52 \\
1.52\end{array}$ & $\begin{array}{l}3.41 \\
2.51\end{array}$ & $\begin{array}{l}2.21 \\
1.92\end{array}$ \\
\hline G-6-P DH & $\begin{array}{l}\text { normal } \\
\text { nephrotic }\end{array}$ & $\begin{array}{l}6.46 \\
4.21\end{array}$ & $\begin{array}{l}6.06 \\
5.88\end{array}$ & $\begin{array}{l}5.70 \\
5.19\end{array}$ \\
\hline $\mathrm{LDH}$ & $\begin{array}{l}\text { normal } \\
\text { nephrotic }\end{array}$ & $\begin{array}{l}34.60 \\
44.58\end{array}$ & $\begin{array}{l}29.41 \\
57.08\end{array}$ & $\begin{array}{l}25.37 \\
45.36\end{array}$ \\
\hline $\mathrm{ICDH}$ & $\begin{array}{l}\text { normal } \\
\text { nephrotic }\end{array}$ & $\begin{array}{l}28.30 \\
26.60\end{array}$ & $\begin{array}{l}19.21 \\
35.13\end{array}$ & $\begin{array}{r}5.64 \\
31.09\end{array}$ \\
\hline GOT & $\begin{array}{l}\text { normal } \\
\text { nephrotic }\end{array}$ & $\begin{array}{l}26.98 \\
29.83\end{array}$ & $\begin{array}{l}12.11 \\
24.86\end{array}$ & $\begin{array}{r}2.07 \\
15.94\end{array}$ \\
\hline GPT & $\begin{array}{l}\text { normal } \\
\text { nephrotic }\end{array}$ & $\begin{array}{l}11.26 \\
17.04\end{array}$ & $\begin{array}{r}7.02 \\
12.78\end{array}$ & $\begin{array}{r}6.34 \\
16.59\end{array}$ \\
\hline
\end{tabular}

Mean value of activity: moles per kilo dry weight per hour

\section{A Radioautographic Study on the Incorporation of $\mathbf{S}^{35}$-Methionine and $\mathrm{H}^{3}$-Glycine in the Experimental Silicopneumoconiosis and Asbestospneumoconiosis}

Zenji Horai, Masayuki Kaneda, Tsunehiro Michizawa, Shinichi Kasahara, Tadahiko Sugimoto and Tomohiko, Okuyama

The 2nd Depertment of Internal Medicine, Nara Medical University, Kashihara

The experimental silicopneumoconiosis and asbestospneumoconiosis of the rats were induced by pertracheal infusion of free silica and blue asbestos suspension. Two experimental groups with above experimental pulmonary fibrosis were reared during 2, 4, 8, and 16 weeks after infusion.

After experimental interval time $\mathrm{S}^{35}$-Methionine was injected intraperitoneally to rats with silicopneumoconiosis and asbestospneumoconiosis and also $\mathrm{H}^{3}$-Glycine was given in the same manner.

The animals were sacrificed at 1 hour after injection of each labels and lungs were embeedded with Bouin solution and radioautographic preparations were made with Kodak $\mathrm{NTB}_{2}$ by dipping method.

In the silicopneumoconiosis and Asbestospneumoconiosis marked uptake of $\mathrm{S}^{35}$-Methionine was observed in the extracellular space around nodules of the lungs at early time anf followed by a slight decreased from then but less uptake in the silicopneumoconiosis.

In the two groups uptake of $\mathrm{H}^{3}$-Glycine was small in number in the extracellular 
space around nodules at 2 weeks after infusion and then increased, but uptake of labels in the asbestospneumoconiosis increased in number as compared with the silicopneumoconiosis.

\title{
Quantitative Cytochemical Study of Plant Gell Nuclei by Means of Ultrasoft X-ray Microradiography
}

Tosisuke Hiraoka

Dept. of Botany, Fac. of Science, Kyoto University, Kyoto

Ultrasoft X-ray microradiography permits us to measure the mass of an individual cell or cell element, and it may be used as a sensitive microbalance in the field of cytochemistry. Cytochemical study of plant cell nuclei along this line were carried out in our laboratory, and some of the results obtained will be given below. 1) In Tradescantia paludosa, most of the petal cell nuclei did not show any DNA turnover, but showed RNA and protein turnover as revealed by autoradiography. According to our X-ray microradiographic measurement, these metabolic nuclei gave a mode value of $2.6 \times 10^{-10} \mathrm{~g}$ and showed a rather wide variety of mass. 2) In the pollen mother cell nuclei undergoing meiosis, the DNA synthesis occurred before leptotene and the protein synthesis before zygotene as demonstrated by microspectrophotometry and autoradiography. Our Z-ray microradiographic study revealed that the chromatin mass was $2.1 \times 10^{-10} \mathrm{~g}$ in interphase, increased to reach $4.2 \times 10^{-10} \mathrm{~g}$ before zygotene, and remained constant through the first prophase. It was reduced by half in the first anaphase, and again in the second anaphase. 3) In Lilium speciosum, the tapetum cell nuclei were isolated and subjected to sequential extractions to remove nucleic acids and basic proteins. Before and after these extractions, X-ray microradiograms were taken. These procedures permitted us to analyse the chemical composition of these cell nuclei. In this case, nucleic acids accounted for $30.8 \%$ of dry weight, basic proteins $44.2 \%$ and non basic ones $25.0 \%$.

\section{A Microfluorometric Study on the Ghromatin Fraction Isolated from Rat Liver}

\author{
Masa-oki Yamada, Hironobu Yamada, Sachiko OHnishi
}

\section{Department of Anatomy, School of Medicine, Tokushima University, Tokushima}

Bindings of acridine dye with DNA have been resulted in the fluorescent change relating to mol ratio of DNA-phosphorus (DNA-P) to dye molecule by Bradley (1959) and Lerman(1961).

The secondary fluorescence of acridine orange( $\mathrm{AO})$ was applied for the study on interactions between DNA and its relating proteins by us. The fluorescence of DNA-AO complexes was quantitatively determined in using a rapid-recording microfluorophotometer(YAMADA, 1966). Such a kind of interaction was also 
studied on the chromatin fractions prepared from rat liver by modified methods of Paul-Gilmour(1966) and Marushige-Bonner (1966).

AO-fluorescence of the chromatin was compared with that of DNA in varied mol ratios of DNA-P to AO. This fluorescent titration of the chromatin was similar to that of DNA. The fluorescence was also titrated by increasing basic proteins (or poly-lysine) to the chromatin as well as to DNA. The saturated points of the chromatin with basic proteins, thus titrated, were also similar to those of DNA.

From these findings, it is reasonably assumed that most of DNA in the chromatin fractions is quite weakly bound to their proteins and the proteins are replaced by stronger basicity of proteins for weaker one.

\title{
A Microfluorometric Study on Rat Liver Ribosomes
}

\author{
Masa-oki Yamada, Yozo Takehisa and Taeko Yamaughi
}

Lab. of cytochem., Dept. of anatomy, School of medicine, Takushima University, Tokushima

By utlizing a rapid-recording microfluorometer in combination with microcubet deviced in our laboratory (YAMADA 1968), fluorometry of minute amounts $(5 \mu \mathrm{l})$ of ribosomes has been in progress.

The change of the ribosomal structure takes place by adding or removing $\mathrm{Mg}^{++}$from ribosomes. This relation fully reflects on the fluorescence of ribosomeacridine orange (AO) complex. Besides, in combined applications of $\mathrm{AO}$ on sucrose density gradient centrifugation with dissociated ribosomal subunits with EDTA or $\mathrm{KGl}$, the fluorescent site in the ribosome is mainly distributed in the smaller subunit particle. But a considerable higher fluorescence appears in the larger subunit dissociated with EDTA, which is well agreeable with inactivation and destruction of the subunit.

Successively deproteinized ribosomes with $\mathrm{LiCl}$ show a higher fluorescence than untreated ones and most of this increase derives from the removal of split proteins from the larger subunit particles.

The fluorescence of residual particles is made lower by the digestion with RNase.

Thus, these fluorometric change seem to be an indicator of the conformational change of ribosomal structure, because AO-fluorescence of ribosomes is modified in parallel to the formation of AO-rRNA complex.

The Method of Cell Isolation From Fixed Tissues for Microspectrophotometry of Nuclear DNA Gontent. the 3rd Report

(A study on the nuclear DNA content of gastric cancer.)

Shunta Hirose, Zenji Iwasa, A. K. A. RazzaQ, Nobuhiro Murai, Ryotaro Yamada, Masayuki Yasutomi, Dennosuke JinnaI.

Department of Surgery, Osaka University Medical School, Osaka

In the 9 th and 10th General Meeting, we reported that the successive treatment with EDTA, crude Stem Bromelain and ultrasonic wave was effective to prepare 
free cells from fixed tissues for microspectrophotometric determination of DNA content. This new method made it possible to measure the DNA content of the cells in a microscopic lesion separately from the cells in a surrounding tissue.

Now we applied this method to the measurement of the nuclear DNA content of gastric epithelial cells in normal and various pathological conditions.

The DNA content of normal gastric epithelial cells showed a modal peak at $2.0 \mathrm{n}$ arbitrary units, and ranged within $4.0 \mathrm{n}$ arbitrary units.

The DNA content histogram of the gastric epithelial cells with intestinal metaplasia showed same pattern as that of normal jejunal epithelial cells. When we divided the intestinal metaplasia into superficial and glandular part, and jejunal epithelium into villi and glandular part, the epithelial cells in superficial part and villi showed a modal peak at 2.0n, but both of the glandular cells showed a peak at hyper-2.0n.

In so called borderline cases, i.e. cased difficult to be classified morphologically as benign or malignant, two out of six lesions showed same pattern as cancer in DNA content histogram, and one lesion showed completely normal pattern.

In two cases of early gastric cancer in which small area of simple carcinoma was surrounded by tubular adenocarcinoma, the range of distribution in DNA content was wider in the former than in the latter, but modal peaks of them were seen at the same position in the histogram. These data, along with histological findings, strongly suggested the possibility of changing from adenocarcinoma to simple carcinoma.

Comparison of DNA contents of the cancer cells in primary lesion and metastasized lesion in lymph nodes revealed that the range of distribution in the latter was always narrower than in the formar and, in some cases, the stem line cells of the metastasized lesion contained less DNA than those of the primary lesion.

\title{
Microfluorescence Photometric Study on the Localization of the Lens Proteins in the Developing Lens
}

\author{
Akira Ikeda and Juzo Sawano \\ Dept. Anatomy, Hiroshima University, Hiroshima
}

Direct measurements of cellular fluorescence following with fluorescent specific lens proteins antibody can provide objective evaluations which are more refined than subjective estimates, and which can reveal the quantitative antigenetic differences and localizations in the developing lens.

An Olympus double beam microspectrophotometer (DMSP-II) which we added microfluorescence photometric system was used.

In this apparatus, it can be possible to measure not only the fluorescence but also the total proteins concentration by the microspectrophotometric system in the same developmental stage samples.

The measurement had been done under the following conditions; measuring area : $7 \mu$, exitation light : $365 \mathrm{~m} \mu$, emission light : $536 \mathrm{~m} \mu$ and scanning speed of the samples stage : $1 / 4 \mathrm{~mm}$ per min.

In the newt lens, the first fluorescence had been measured in a few central cells 
of the lens placode, mainly close to the nuclei in the basal parts of the cells. Rapidly the cells became fluorescent and the whole lens was completely positive. In the following stage, the lens fibers gradually became to lose the some fluorescence. This continued until the lens core was completely negative, while the total lens proteins concentration had been kept in constant.

\title{
Fluorescence and Electron Microscopic Study of Ghromaffin Gell in Heart
}

\author{
Nagayasu Otsuka \\ Department of Anatomy, Okayama University Medical School, Okayama \\ Нitoji Окамото \\ Internal Medicine, Kyoto Prefectural University of Medicine, Kyoto
}

The chromaffin cells in the cyclostome (Entosphenus japonicus) heart was investigated in the fluorescence and electron microscope.

In fluorescence microscope, a large number of multipolar cells emitting a green to yellow-green fluorescence could be localized to the surface of the muscle bundles outlining the walls of the lumina of the heart. These cells were most numerous in the atrium. No adrenergic fibres could, however, be found in the heart of these species.

The eiectron microscopical study of the heart has revealed the presence of a large number of specific granular cells similar to those of the adrenal medulla in higher vertebrates. The cell granules which are regarded as storage sites for catecholamines are strongly osmiophilic and have a diameter of about $0.15 \mu$.

\section{A Fluorescence Histochemical Study on the Occurrence of Biogenic Monoamines in the Carotid Bodies of Various Vertebrate Species}

\author{
Shigeru Kobayashi \\ Department of Anatomy, Niigata University School of Medicine, Niigata
}

Carotid bodies of mammals (human fetus, dog, rat, mouse) and a bird (Uroloncha domestica) and carotid labyrinths of amphibia (Rana nigromaculata, Bufo bufo japonicus, Cynops pyrrhogaster pyrrhogaster) were studied using Falck-Hillarp fluorescence histochemical technique for biogenic monoamines.

In mammalian and avian carotid bodies, the cytoplasm of the chief cells showed green or yellow-green fluorescence after treatment with formaldehyde gas. In amphibian carotid labyrinths, cells with intense yellow fluorescence occurred within the trabecules.

Bo fluorescence was demonstrated in the nerve fibers and terminals surrounding the chief cells which were observed by electron microscopy. 


\title{
Subcellular Localization of Enzymes Related to Dopamine Biosynthesis and Metabolism in Bovine Gaudate Nucleus
}

\author{
Ikuko Nagatsu \\ Department of Anatomy and Physiology, \\ Aichi Prefectural College of Nursing, Moriyama-ku, Nagoya
}

Subcellular localization in bovine caudate nucleus of the enzymes related to biosynthesis and metabolism of dopamine; tyrosine hydroxylase, DOPA decarboxylase, monoamine oxidase, and catechol-0-methyltransferase, were examined. The subcellular fractions were isolated from crude mitochondrial fraction by sucrose density gradinet according to the procedure of Whittaker. Synaptic vesicles were isolated after hypotonic treatment of the crude mitochondrial fraction according to the procedure of Maynert. The purity of each fraction was examined by electron microscopy.

Tyrosine hydroxylase activity was localized mainly in nerve endings and microsomal fraction, and in some part in soluble fraction. Synaptic vesicles also contained tyrosine hydroxylase activity. Monoamine oxidase was seen predominantly in mitochondria. The low activity of monoamine oxidase in nerve endings may be attributed to the mitochondria which were contained in the fraction. DOPA decarboxylase activity was found predominantly in soluble fraction. Catechol-0methyltransferase activity was found in soluble fraction and microsomal fraction.

These results show that there exist 2 forms of tyrosine hydroxylase in the homogenate of the bovine caudate nucleus; mostly particle-bound enzyme and a small fraction of soluble enzyme. The particle-bound enzyme appears to be localized in nerve endings, and probably in synaptic vesicles.

\section{Histochemical Studies on the Rat Brain in Renal Failure}

\author{
Yuta Ommura, Akira Mryakawa, Masatsugu Ishikura \\ Yuichi Shinoda and Shunichi Abe
}

\section{Second Department of Pathology, Hokkaido University School of Medicine, Sapporo}

When the kidney is severely damaged, the various cerebral symptoms appear clinically. Morphologically, however, there are no specific changes in the nerve cells and stroma of the brain of uremic subjects except for the circulatory disturbance such as cerebral edema. In this respect, we have investigated the histochemical changes of the brain of the rat with experimentally induced renal failure. We have also compared the changes of the brain in acute renal damage with those in chronic renal failure, and further mentioned the time-correlation of the changes in the rat brain and kidney.

In one group of the albino rats, acute renal failure was induced either by the operative procedure or the subcutaneous injection of mercuric chloride. In the other group, natrium-N4-acetyl sulfathyazol was injected intraperitoneally over a 
long period with the object of inducing chronic renal failure due to chronic interstitial nephritis.

Marked cerebral edema was observed in the brain of the rat with the value of BUN over $60 \mathrm{mg}$ per $100 \mathrm{cc}$ both in acute and chronic renal failure. The typical dixanthyl urea crystals were demonstrated in the tissues of the rat brain, but the nerve cells and stroma showed no specific histological alterations.

Histochemically, the lactate dehydrogenase and succinic dehydrogenase activities in the renal tubular epithelium and nerve cells were predominantly reduce The alkaline phosphatase activity in the tubular epithelium and the walls of the cerebral vessels was also descreased early in the course of the acute renal damage. In the chronic renal failure, the activities of lactate dehydrogenase, succinic dehydrogenase and alkaline phosphatase were considerably reduced in the brain and kidney as seen in the acute group. Acid phosphatase in the rat brain, which is presumed to be localized within lysosomes and play an important role in phagocytic processes intra- and extracellularly, showed either normal or moderately increased activity.

\title{
Histochemical Studies on the Morphology of the Golgi Apparatus in the Neurons of Suraoptic and Paraventricular Nuclei of the Normal and Dehydrated Rabbits.
}

\author{
Koichi IrjIma
}

Anatomy Department, Tokyo Medical and Dentail University, Tokyo

Histochemical studies have been conducted on the morphology of the Golgi apparatus by applying the thiamine pyrophosphatase method (Novikoff and Goldfischer, 1961) to the neurons of supraoptic and paraventricular nuclei of normal and dehydrated rabbits. The neurons in both nuclei were classified into five categories on the basis of the morphology of the Golgi apparatus. The number of neurons was counted to evaluate the percentage of each category in the whole nucleus.

Neurons have many vesicles which show the tendency to form clusters. Such clusters are present also in the "basal bodies". The Golgi apparatus is localized near one side of the nucleus in many neurons. The neurons indicate cyclic acitivity of resting, anabolic and catabolic stages under normal conditions.

During dehydration, the Golgi apparatus goes through the three stages of network formation, the increase of the budding-off process and later on disintegration. The supraoptic nucleus reacts to the TPPase test more severely than paraventricular nucleus, whereas the former goes through the stages more slowly than the latter. The paraventricular nucleus also reveals sensitivity to osmotic stress. Other hypothalamic neurons do not show such changes of the Golgi apparatus (noted above) during dehydration. 


\title{
The Effects of Lecithin on the Lysosomal Membrane of the Rat Liver Cells. I. The stabilization effects of lecithin on the labilization caused by Triton X-100 in vitro.
}

\author{
Takuma Saito, Hiroshi Mayahara and Kazuo Ogawa
}

Department of Anatomy, Kansai Medical School, Moriguch, Osaka

The process of lysosomal membrane labilization caused by Triton X-100 and the effects of lecithin, a main component of membrane phospholipids, on the labilizing action of Triton X-100 were studied by means of the light and electron microscopical cytochemistry. The degree of labilization and stabilization of the lysosomal membrane was judged by the degree of leakage of acid phosphatase from lysosomes.

The liver of normal SD rats was fixed with $4 \%$ formaldehyde (2 hours) or $2 \%$ glutaraldehyde (30-60 min) and then $40 \mu$ frozen sections were made. The sections were pre-incubated in $0.5 \%$ Triton X-100 in various length of time $(0.5,2,5,10$, 20 , and $30 \mathrm{~min}$ ) and processed for the demonstration of the acid phosphatase activity. To see the stabilization effects, $5 \%$ lecithin was added into the Triton X-100 preincubation medium.

The acid phosphatase activity was leaked out from almost all lysosomes in the liver cells after treatment with Triton X-100 for $30 \mathrm{~min}$. The degree of diffuse staining around lysosomes was increased as the duration of Triton X-100 treatment was prolonged. Partial disappearance of the lysosomal membrane was observed in some cases under the electron microscope. When lecithin was added into the pre-incubation medium, the leakage of acid phosphatase from lysosomes was prevented. It is concluded that lecithin possesses the stabilizing effects on the lysosomal membrane labilization caused by Triton X-100.

\section{The Effects of Lecithin on the Lysosomal Membrane of the Rat Hiver \\ Cells. II. The protective effects of lecithin on the central necrosis caused by carbon tetrachloride $\left(\mathrm{CG}_{4}\right)$}

\author{
Hiroshi Mayahara, Takuma Saito and Kazuo Ogawa \\ Department of Anatomy, Kansai Medical School, Moriguchi, Osaka
}

Male SD rats were injected intraperitoneally with $400 \mathrm{mg}$ of lecithin (dissolved in $5 \%$ glucose by ultrasonication) $/ 100 \mathrm{~g}$ body weight daily for 3 consecutive days, then $1 \mathrm{ml}$ of $10 \% \mathrm{CGl}_{4}$ dissolved in liquid paraffin $/ 100 \mathrm{~g}$ body weight was injected intraperitoneally. Rats were sacrificed 1 hour to 10 days after the $\mathrm{CCl}_{4}$ injection. Livers fixed in $2 \%$ glutaraldehyde for 1 to 2 hours were examined for acid phosphatase activity by both light and electron microscopy. Two types of controls were used: control 1 received a daily lecithin injection for 3 consecutive days but no $\mathrm{CCl}_{4}$, and control 2, which received a daily injection of glucose for 3 consecutive days and a single $\mathrm{CCl}_{4}$ injection.

Rats in control 2 revealed the typical picture of central necrosis in the hepatic lobule caused by $\mathrm{CGl}_{4}$, whereas rats receiving lecithin and $\mathrm{CCl}_{4}$ did not show any 
appreciable degree of central necrosis. Rats in control 1 also reveled almost normal findings with some increase in the acid phosphatase activity in Kupffer cells.

Thus, the conclusion was that lecithin had protective effects on the hepatic cellular damage caused by $\mathrm{CCl}_{4}$.

\title{
Electron Microscopic Observation on the Acid Phosphatase Activity of the Tubular Cells in Rats.
}

\author{
Shuji Suko \\ Defartment of Pathology, Kumamoto University School of Medicine, Kumamoto
}

Acid phosphatase activity of the rat renal tubular cells, especially the proximal tubular cells, was demonstrated by use of enzyme cytochemical methods under the electron microscope. In order to examine the relationship between primary lysosome and secondary lysosome, large doses of dextran fluid were intraperitoneally administrated in the rat. Pinocytotic vacuoles were formed in various size at the cytoplasmic areas beneath the brush border in the early stage after the administration. The vacuoles gradually increased in size. Primary lysosome always contained the acid phosphatase activity on and inside those membranes. Pinocytotic vacuoles themselves did not show the acid phosphatase activity, but when metabolized, they came to have the reaction products for enzyme. It is considered from these results that secondary lysosome presumably are closely related with the primary lysosome.

\section{The Development of the Method for the Demonstration of NADPH-ferricyanide Reductase Activity and its Application in Several Tissues of Rats.}

\author{
Yasuhiro Ago and Kazuo Ogawa \\ Department of Anatomy, Kansai Medical School, Moriguchi, Osaka
}

As an extension of our studies on the copper ferrocyanide method, the method for the demonstration of NADPH-ferricyanide reductase activity was developed. The incubation medium consists of $20 \mathrm{mg} \mathrm{NADPH}, 13.0 \mathrm{ml} 0.1 M$ phosphate baffer, $\mathrm{pH} 7.0,1.3 \mathrm{ml} 0.1 \mathrm{M}$ sodium citrate, $2.0 \mathrm{ml} 30 \mathrm{~m} M$ copper sulfate, $1.7 \mathrm{ml} \mathrm{d}$. d. w., $2.0 \mathrm{ml} 5 \mathrm{~m} M$ potassium ferricyanide and $3.0 \mathrm{~g}$ sucrose. It was observed in the preliminary experiment that potassium sodium tartrate caused more diffusion of the final reaction products than sodium citrate.

Fresh tissues (cerebral cortex, liver, heart and kidney) of rats were used. Incubation was carried out aerobically as well as anaerobically. In some cases tissues from the rat kept in complete dark for 24 hours were used.

The NADPH-ferricyanide reductase activity was extremely low in tissues taken from the normal rats. The enzymatic activity in specimens incubated under anaerobic conditions was higher than that incubated under aerobic conditions. The enzymatic activity was much higher in all tissues taken from the rats kept in dark 
than that from the normal rats, indicatiny the diurnal change of the activity.

In the enzymatically positive tissues the activity was observed in mitochondria. In mitochondria the reaction products were observed in the membrane system including the outer membrane, the intracristal space and the outer space. No reaction product was observed in the matrix. Antimycine A inhibited some deposit formation. No activity was found in specimens incubated in the substrate free medium.

\title{
Histochemical and Electron Microscopic Studies on Aspartate Transaminase in Experimental Myocardial Infarction
}

\author{
Yasuo KIsHino \\ Department of Pathology, School of Medicine Tokushima University, Tokushima
}

Myocardial infarcts were induced in rats by the ligation of left coronary artery. Histochemicaliy the GOT activity in infarcted areas was diminished at 12 hours after coronary occlusion and a mottled appearance due to loss of GOT content in individual fibers. After 24 hours, the activity in injured region was markedly decreased. Electronmicroscopic observation at 6 hours after coronary occlusion revealed disruption of myofibers and swelling of mitochondria, and cristae within mitochondria were irregularly dilated. The fine particles, which were interpreted as reaction product due to GOT reaction, was still deposited at a surface membranes, nuclear membranes and cristae of mitochondria. After 12-24 hours, together with disruption of myofilaments and disorganization of mitochondria, the appearance of large dense intramitochondrial granules and aggregation of cristae were remarkable. GOY activity in these mitochondria was decreased or absent and presumably the dense intramitochondrial granules were not related with the fine particles detected GOT activity. After 36 hours, the contuinuity of mitochondria were broken and no GOT activity was demonstrated at the cristae of the ruptured mitochondria. Collagen fibers were seen between disrupted myofibrils and ruptured mitochondria. The result of this and other biochemical studies support the concept that the decrease of mitochondrial GOT activity was later than supernatant GOT after myocardial infarction.

\section{Tetrazotized Benzidine as an Azo-Coupling Agent for the Histochemical Demonstration of Phosphatase Activity}

\author{
Reiko YoкотA \\ Dept. of Anatomy, Iwate Medical College, Morioka
}

Tetrazotized benzidine (TB) and hexazotized New fuchsin (HN) were used as capture reagents in combination with 1-naphthyl phosphate for demonstration of alkaline and acid phosphatases. Reaction products were brown or reddish brown in colour. They were electron dense, $20-70 \mathrm{~nm}$ in diameter, and insoluble 
in organic solvents such as alcohol, acetone and b-nutyl glycidyl ether (QY-1).

By using these reagents, alkaline phosphatase activity was found on the limiting membrane of microvilli and lateral cell membrane and on the Golgi complex (TB and $\mathrm{HN}$ ) of the absorbing cells of the rat duodenum. Under the light microscope, acid phosphatase activity of intracytoplasmic granules (epithelial cells of the proximal convolution of the rat kidney) was observed according to the method above mentioned.

\title{
Electron-Microscopic Localization of Alkaline Phosphatase Activity in Hyperfunctional and Neoplastic Epithelium of the Mammary Gland of Female Rats
}

\author{
Sotokichi Morin, Kiyoshi Kon, Soichi Tominaga and Toshiyuki FujıI \\ Department of Pathology, Kansai Medical School, Moriguchi)
}

Distribution of alkaline phosphatase activity in the resting mammary gland of young adult female rats of Sprague-Dawley's strain was reported previously by means of Mayahara et al's method for electron-microscopic observation (Acta Histochem. Cytochem., 2: 199, 1969). These findings were applied for the controls in this presentation.

Less deposition of the reaction product was seen along the basal plasma membrane of the hyperfunctional glandular epithelium in the mammary gland with milk congestion, in general. This alteration was prominent on the basal plasma membrane touching the basement membrane, and it was slight on the basal plasma membrane closed with myoepithelial cell. Its decrease and disappearance were more prominent in the atrophic glandular epithelium caused by chronic milkcongestion. In this hyperplastic mammary gland, the precipitate was found neither along the luminal surface nor on the microvilli.

Induced mammary carcinomas with 7, 12-DMBA were also observed by the same method. In the papillary adenocarcinoma, grade 1, more abundunt deposition of the reaction product was seen along the folded plasma membrane of the tumor cells. It was detected not only the basal plasma membrane but also the lateral plasma membrane. Sometimes, it was found in the lumen, but it was detected neither along the luminal surface nor on the microvilli. The precipitate was, however, never detected in the carcinoma simplex, grade 3, even on the basal plasma membrane of the tumor cell touching the basement membrane. The deposition of the reaction product could be seen on the prominently hyperplastic microvilli or in the dilatated lumen of the tumor tissues sometimes, which were mainly some degenerative portion of the mammary carcinomas, grade 2 or 3 . The precipitate was observed also along the smooth luminal surface of the atrophic tumor cell following the host's ovariectomy.

The activity was never detected in the intracytoplasmic organellas of the glandular epithelium of the hyperplastic and neoplastic mammary glands. The localization and the intensity of alkaline phosphatase activity in the myoepithelial cell were hardry modified by the above-mentioned conditions of the mammary gland. 


\title{
Ultrastructural Observation and Phosphatase Activity on Tumor Gell of LY 336
}

\author{
Morio Kato, Takuro Suzuki, Kazuto Nokubi and Masaru Anbe \\ Department of Anatomy, Toho University School of Medicine, Tokyo
}

Ultrastructure and non-specific phosphomonoesterase activity were observed on the tumor cells of LY 336.

Many varieties of the form can be found on the tumor cells of LY 336. Among these, there are a few cells including various sized vacuole in their cytoplasm. They have been considered as one of the degenerating process of the tumor cell, but the real origin of them is yet uncertain.

On these vacuolized cells, they have poor cell organelle, the larger the vacuole grows, the poorer the microvilli can be seen on the inner surface of the vacuole.

With reference to alkaline phosphatase, the most of cell junction reveal intense activity, cell membrane of some tumor cells moderate or strong activity, but no activity is observed on inner surface of the vacuole.

In regard to acid phosphatase, no relation has been proved between the activity of the enzyme and degenerating graduation of the tumor cells.

\section{Electronmicroscopic Cytochemistry of Human Lung and Lung Carcinomas}

\author{
Tsutomu Koide, Keiichi Watanabe and Yukio Shimosata \\ Pathology Division National Cancer Center Research Institute, Tokyo
}

Localization of acid and alkaline phosphatase activity in human lung epithelia was observed by electron microscopy. Alkaline phosphatase activity was found in the cell membrane and microvilli of goblet cells, secretory cells of bronchial glands and Type II alveolar epithelial cells. Occasionally, the membrane of lamellar inclusion bodies of Type II cells, cell membrane and pinocytotic vesicles of both Type I cells and myoepithelial cells of bronchial glands, and rarely the surface membrane of ciliated columnar cells possessed the activity. Acid phosphatase activity was noted in lysosomes of ciliated columnar cells, multivesicular bodies and lamellar inclusion bodies of Type II cells and in what appear to be immature secretory granules of both goblet cells and secretory cells of bronchial glands.

Electron microscopic cytochemistry also disclosed the presence of cells resembling Type II cells and mucus secreting cells in a well differentiated adenocarcinoma, and the presence of both glandular cells and squamous cells in a poorly differentiated adeno- or squamous cell carcinoma. These findings indicate that the tumor cell originated in epithelia of bronchi, bronchioli or alveoli, which are probably of a single cell origin, may manifest characteristics of various cell types of the respiratory epithelium at the site of proliferation of tumor cells. 


\title{
Distribution of Gastric Mucosa-Specific Glycoprotein in Gastric Cancer Tissues as Detected by Immunofluorescence Technique.
}

\author{
Hiroshi Kawasaki and Katsujiro Imasato \\ 1 st Department of Pathology, Kurume University School of Medicine \\ Eiji Кімото and Mutsuya ТАкeuchi \\ Institute of Clinical Pathology, Kurume University School of Medicine
}

The epithelial glycoprotein, isolated from human gastric mucosa, was employed for the immunization into rabbits to obtain antisera. Though this glycoprotein possessed the chemical composition similar to that of the so-called water-soluble blood group substance, it gave a precipitate line in agar gel against antiserum even after a complete absorption with appropriate red cells until no more hemagglutination occurred. On the Ouchterlony assay against various tissue extracts, this glycoprotein material was found to exist exclusively in human gastric mucosa, only poorly in intestinal mucosa but not in other tissues.

On the immunofluorescence preparations from the normal stomach, this material distributed intensely in mucoid cells and secreted mucus within the mucosa. In gastric cancers, though the well-differentiated ones of nonsecretory activity were devoid of such material, the diffusely and invasively proliferated ones possessed or secreted the same or cross-reacted antigenic glycoprotein, correlating well with PAS staining.

Immunofluorescent staining was carried out on the metastasized cancer cells in a case of Krukenberg tumor with gastric cancer as a primary lesion. The cancer cells, especially of signet ring form, in the stomach as well as the metastasized organs including omentum, ovary, rectum, lung and liver were intensely stainable with the FITC-labeled antibody, though the normal areas of the latter organs were scarcely fluoresced. It might, therefore, be deduced that such metastasized cancer cells in various organs apart from the primary gastric lesion persisted in producing or secreting the epithelial glycoprotein specific for the gastric mucosa or cross-reacted with the latter.

\section{The Site of Complement Components, C 3 and C 4 Demonstrated by Immuno-fluorescent Antibody Technique}

\author{
Yasuo Mizuno, Takao Tsuji, Masami Sato, Hiroshi Hirata, \\ Hajime Nosaki, Yasuyuki Oнta, and Kiyowo Kosaka
}

\section{The 1 st Department of Internal Medicine, Okayama University Medical School, Okayama}

The site of the individual serum protein $\mathrm{G}_{1}$ components, $\mathrm{C}_{3}$ and $\mathrm{C}_{4}$ was visualized by the method of an immuno-fluorescent antibody technique.

As component $\mathrm{C}_{3}$ and $\mathrm{C}_{4} \boldsymbol{\beta}_{1 C} /{ }_{1 A}$ and $\boldsymbol{\beta}_{1 C}$-globulin, respectively, was studied. The antibodies to $\beta_{1 C} / 1_{1 A}$-globulin was purchased from the Hyland laboratories, and the antibodies to $\beta_{1 E}$-globulin was prepared by Dr. Torisu et al. of the National 
Cancer Center Research Institute. Fluorescein isothiocyanate was labeled as described elsewhere. The materials studied were fetal livers 8 and 34 weaks old, a normal liver of autopsy case died of cerebellar tumor, a liver of hepatoblastoma, two livers of hepatoma, 6 liver in the chronic active hepatitis and three livers of liver cirrhosis. The results were as follows:

The localization of $\beta_{1 C} /{ }_{1 A}$-and $\beta_{1 E}$-globulin was present in the liver cells as early as fetal life of 8 weeks. The amount increased in the adult liver cells, though the localization within the lobule was not consistent. Besides the liver, the components were found in the red pulp of the splleen, median seized mononuclear cells in the lymphgland and secretory glands of the stomach and intestive. $\beta_{1 C} / 1_{1-}$ and $\beta_{1 E}$-globulin in livers of hepatoblostoma and hepatoma was decreased. A remarkable deposite of the $\beta_{1 C} /{ }_{1 A}$ - and $\beta_{1 E}$-globulin was present in the areas of the loss of limiting plates in the liver of chronic active hepatitis and postnecrotic cirrhosis. The immuno-globulin $\mathrm{G}$ was present in the some areas.

From the above observation, the author draw following conclusions. Firstly, the dominant site of the complement components $\mathrm{C}_{3}$ and $\mathrm{C}_{4}$ formation was in the liver cells. Secondly, simultaneous localization of the complement components and immuno-globulin $\mathrm{G}$ in the areas of the loss of limiting plate was explained to be the site of cell damage induced by an antigen-antibody complex.

\section{No. 42 Particular Affinity Observed in Gamma Globulin Fraction to the $\alpha$-Cell Cytoplasm of Langerhans Islet}

Takayuki Harada and Shigeru Morikawa

\section{Department of Pathology, Chest Disease Research Institute, Kyoto University, Kyoto}

In the course of the investigation for the localization of enzyme antigens by fluorescent antibody technique, it was found that fluorescent labeled rabbit gamma globulin possessed particular affinity to $\alpha$-cell cytoplasm of islet of Langerhans in the frozen sections of rabbit pancreas.

This phenomenon has been further investigated.

Results:

1) Normal non-conjugated rabbit, guinea pig and human gamma globulin had the affinity to the islet cells of rabbit pancreas as well as fluorescein labeled gamma globulin. On the other hand, normal bovine, sheep, mouse and rat gamma globulin had little affinity to those cells.

2) It was revealed by immunoelectrophoretic assay that there were two fine precipitin arcs between normal rabbit serum and rabbit pancreas homogenate. One of them located in $\alpha$-globulin resion and another belonged to $\alpha$-globulin.

3) Fab fraction from papain digested rabbit gamma globulin did not show any reactivity to the islet cells. $\mathrm{Fc}$ fraction did not give constant results by both blocking test and indirect staining with anti-rabbit gamma globulin sheep santierum. It was assumed that this phenomenon was due to the property of gammaglobulin molecule, or Fc portion, not to antigen-antibody reaction by Fab portion.

4) Sera from three of eight rabbits examined showed the affinity to their own pancreatic islets. 


\section{Study on Staining Patterns of Antinuclear Factor Using Enzyme-Labelled Antibody Method}

Yoshifuji Matsumoto ${ }^{1}$ and Shinichiro Umemura ${ }^{2}$

\section{Department of Pathology, Nihon University Medical School, Tokyo}

The staining patterns of antinuclear factor(ANF) using immunofluorescence have already been investigated, and usually classified into four or five types. The present experiments were done to investigate the staining patterns of ANF using enzyme-labelled antibody method, and compared with immunofluorescence. The conjugation of peroxidase to rabbit anti-HGG antibody was carried out with $0.5 \%$ FNPS or $1 \%$ glutaraldehyde. In case of FNPS enzyme-labelled antibody was purified with Sephadex G-200, and for glutaraldehyde the enzyme was conjugated to purified antibody, which was prepared using water insoluble immunoadsorbent. Good stainings were obtained, when glutaraldehyde was used. The staining of ANF from peripheral blood smear was done by the indirect immuno-technique, and then peroxidase was reacted after Karnovsky(1966). There was no difference in staining patterns obtained by using various fixative solutions of different concentration and fixation time. Among $17 \mathrm{ANF}$ positive sera staining patterns were newly classified as follow: diffuse type, perinuclear type, flecked type, fine granular type, and thready type. These types do not correspond to that of immunofluorescence. Dilution of sera gives no change in staining patterns. Each serum almost always gives only one type of staining patterns, but some two or three types from one specimen.

Present address, 1: 2nd department of internal medicine Nagoya City University Medical School, Nagoya

2 : department of pathology Nihon University School of Dentistry, Tokyo

\section{Problems of Peroxydase-Labeled Antibody Technique. \\ ... Quantitative Analysis of Conjugation... \\ Kenichi Kozima, Takeshi Murohashi and Itaru Kinara \\ Division of Blood Transfusion, Department of Medicine and Department of Pathology, University of Niigata, Niigata}

Some technical problems of labeling of horse radish-peroxydase (PO) with antibodies were examined. To our experience, glutaraldehyde (GA) seemed to be superior to FNPS as the bifunctional agent concerning the yields and staining ability of the conjugates produced.

Conjugation with GA was performed according to the method of Avrameas et al. However, many technical problems remain still to be solved. Our present report deals chiefly with the quantitative analysis of conjugation.

Gel-filtration of PO (C.F. Boehringer, Type II, RZ 0.6) through Sephadex 
G 100 column induced reversal of ratio of OD $403 \mathrm{~nm} / \mathrm{OD} 280 \mathrm{~nm}$.

To $5 \mathrm{ml}$ of three different mixtures (30,45 and $60 \mathrm{mg}$ PO $+25 \mathrm{mg}$ gamma-globulin) were dropped $0.25 \mathrm{ml}$ of $1 \% \mathrm{GA}$ and gently stirred for 2 to $3 \mathrm{hr}$ at room temperature. Aliquots of each mixture in various stages of conjugation were subjected to quantitative analysis.

The ratio of uncoupled PO to the total PO remained almost unchanged even if the reaction time was prolonged from 2 to 3 hours. Insolubilization due to excessive conjugation occurred in almost one-third of the total gamma-globulin in the first mixture with the smallest quantity of $\mathrm{PO}$, in other words, relatively the largest quantity of GA. The molecular ratios of PO to gamma-globulin in the final products were distributed between 2.4 and 5.7, the largest value in the first mixture.

Moving of the peak OD of the conjugates, application of labeled antibodies to tissue blocks for the electron microscopic examination and others were discussed.

\title{
Electron Microscopic Immunocytochemistry of the Liver Microbody Enzymes. I. Catalase.
}

\author{
Sadaki YокотА \\ Department of Anatomy, Shinshu University School of Medicine, Matsumoto
}

One of the microbody enzymes, catalase was examined with the enzyme-labeled antibody technique. Goat antibody against rabbit $\gamma$-globuin used as an indirect antibody was labeled with horseradish peroxidase (RZ 1.5, Sigma) according to the glutaraldehyde method of Avrameas ('69). Purified bovine liver catalase (O.D. ratio of $407 \mathrm{~m} \mu / 276 \mathrm{~m} \mu$ was about 1 , Kat. f. was 50,000 ) was prepared by chromatography of crude calatase powder (Sigma) on DEAE-cellulose. The enzyme $(5 \mathrm{mg} / \mathrm{ml})$ was emulsified in an equal volume of Freund's complete adjuvant and injected intramuscularly into white rabbits. Rabbit anti-catalase sera were collected 4 weeks after the injection. Small blocks of fresh bovine liver were prefixed in buffered ( $\mathrm{pH} \mathrm{7.2)} 1$ and $4 \%$ formalin or 1 and $2.5 \%$ glutaraldehyde at $0^{\circ} \mathrm{C}$ for 30-120 min. The incubations of the tissue blocks in each antibody medium were carried out for $12-23 \mathrm{hr}$ at $4^{\circ}$ and $37^{\circ} \mathrm{C}$. The tissue blocks were incubated in Karnovsky's medium for 10-20 min, postfixed in 1\% $\mathrm{OsO}_{4}$ and embedded in Epon. For the directidetection of tissue antigen on ultrathin sections, $4 \%$ formalin and $2.5 \%$ glutaraldehyde-fixed tissue blocks were embeedded in methacrylase and HPMA. The method of Kawarai and Nakane('70) was applied to the ultrathin sections.

The reaction products given by peroxidase were localized in microbodies near by the block surface and weakly on erythrocyte membrane. The deposits caused by direct reaction on ultrathin sections were seen on the microbodies of both the methacrylate and HPMA-embedded tissue. The other organelles of hepatocyte was not stained. Therefore, it seems that the bovine liver catalase is almost contained in the microbodies. 


\title{
Histochemical Study of Thyroid Colloid by Azan-Mallory Staining
}

\author{
Futoshi IIDA
}

\section{Shinshu University, The Second Surgical Clinic, Matsumoto}

The Azan-Mallory staining method was applied to thyroid colloid in order to clarify the biological and chemical conditions of it. In experimental condition, the colloid is stained by anilin blue when TSH or Methylthryouacil was given for the animal. When desiccated thyroid or inorganic iodine solution was given, the colloid is stained by azocarmin G. These data suggest us that the released form of the colloid will show basophilic and the stored form will show acidophilic.

In human thyroid, Graves' disease show basophilic colloid in general. In adenoma the colloid is stained either acidophilic or basophilic depending upon the differentiation of follicular structure. In papillary adenocarcinoma the colloid show irregular staining of basophilic and acidophilic which suggest the complicated mechanism of colloid production.

\section{On the Histochemical Significance of the Aldehyde-Fuchsin Staining Method as a Means of Differentiation Between Ceroid and Lipofuscin}

\author{
Ryuei Maeda, Nobuo Ihara, Emyo Nakano and Tadashi Kondo \\ Department of Pathology, Kansai Medical School, Moriguchi
}

Since Gomori (1950) first described the aldehyde-fuchsin (AF) staining method for elastic fibres, the histochemical significance of this method has been subjected to much serious questioning. In the present investigation of pigments in formalin-fixed tissues, it was found that this AF staining procedure presents the merit of enabling a differentiation of AF stain-positive ceroid from lipofuscin which is AF stainnegative, as far as use is each time made of AF staining solution (excepting Gabe's reagent) having an ability to stain ceroid. Therefore, the present authors reexamined the problems connected with AF staining mechanism, and compared the results with the histochemical findings reported by others. Scott et al. (1953) expressed the opinion that the AF-staining method demonstrates, besides the sulfuric $\left(\mathrm{SO}_{4} \mathrm{H}\right)$, sulfon $\left(\mathrm{SO}_{3} \mathrm{H}\right)$ or sulfin $\left(\mathrm{SO}_{2} \mathrm{H}\right)$ radicals, the aldehyde radical.

However, Holzinger (1957) and Iison (1960) disagreed with this opinion, and our own experimental results have led us to do the same one. Furthermore, Lison (1960) and Ortman et al. (1966) described that this staining method shows a positive reaction with the carbonyl radical as well, a view which seems to contradict the fact that the AF stain never shows a positive reaction with lipofuscin which has been proved to have a carbonyl radical (Lillie, 1956).

Sometimes, some parts or kind of ceroid as well as lipofuscin do turn out to be positive after peracetic acid treatment, especially it is found that this kind of ceroid contains a disulfide radical; in this case, the most probable explanation would be that this radical is oxidized by peracetic acid and thus transformed into a $\mathrm{SO}_{3} \mathrm{H}$ - or $\mathrm{SO}_{2} \mathrm{H}$-radical to yield a positive $\mathrm{AF}$ staining reaction. 
On the question as to whether or not the AF stain-positive reaction following oxidation shown by lipofuscin can be attributable to a staining mechanism similar to the one just described, further histochemical investigations are now being carried out. As a conclusion to the present investigation histochemical findings were obtained in support of the opinion that an AF stain-positive reaction in a certain substance suggests the presence of the $\mathrm{SO}_{4} \mathrm{H}-, \mathrm{SO}_{3} \mathrm{H}-$ or $\mathrm{SO}_{2} \mathrm{H}$ - radicals for which radicals the AF stain displays a fairly strict selectivity.

\section{Histochemical Demonstration of Glucose Oxidase}

\section{Shohei Yamashina}

\section{Department of Anatomy and Cell Biology, Tokyo Medical and Dental University, Tokyo}

Glucose oxidase (GOD) in tissue was demonstrated histochemically by the combined utilization of ferricyanide ion and lead ion. The technique was applied to a mold, Penicillium notatum and rat kidney. The former had been known as to produce GOD and the latter was perfused GOD from renal artery. In the consequence, brownish deposits of reaction products could be found on the cell wall of spore, conidiophore and hypha of the mold, and in the glomerulus and intertublarspace of the rat kidney.

It is presumed that the reducing activity of hydrogen peroxide which is generated during enzymatic oxidation of glucose by GOD, changes ferricyanide ion to ferrocyanide ion reacting with lead ion to make whitish precipitates in the tissue.

The results at the same time indicate that hydrogen peroxide can be captured histochemically and the technique may be able to apply to the histochemical detection of some kinds of oxidase by substitution of suitable sabstrates, and furthermore it may be expanded to electron microscopic histochemistry.

\section{Ultrastructural Detection of Glycogen in Rat Liver and Cardiac Muscle}

Tetsuzo Кимамото and Michio Kimura

Department of Anatomy, Wakayama Medical College, Wakayama

The present study is based on the finding that glycogen stains with Gomori's silver-methenamine technique at the fine structural level. Pieces of rat liver and cardiac muscle and pure chemicals of glycogen powder were fixed in $4 \%$ paraformaldehyde, and Epon sections were histochemically stained with silver-methenamine after chromium oxidation for light and electron microscopic observation. Identification of glycogen was confirmed by amylase digestion.

In liver cells, glycogen appeared in rosette and monoparticle form throughout the smooth endoplasmic reticulum and intermitochondrial space. These silver grains exhibited a strong positive reaction. Positive reaction was not observed in nucleus, mitochondria, endoplasmic reticulum, or plasma membrane. 
In cardiac muscle, fine silver grains were observed in well defined locations at the intermyofibril space and at the I-band.

Light and electron microscopic detection of pure chemicals of glycogen powder was carried out using the chromium-silver-methenamine technique, and compared with results obtained by use of common uranyl and lead staining. Glycogen particles demonstrated a strong postive reaction to silver-methenamine, moderate to strongly positive to lead stain, and no reaction to uranyl stain.

\title{
A Cytochemical Study of the Intracellular Localization of Uridine Diphosphate Glucose Glycogen Glucosyltransferase, Using the Centrifugal Fraction Techniques and Electron Microscope
}

\author{
Akiko Fujisaki, Teruo Imamasa and Tadao Takeughi \\ Department of Pathology, Kumamoto University School of Medicine, Kumamoto
}

Intracellular localization of the phosphorylase and UDPGlucose-glycogen glucosyltransferase (UDPGGT) activity was observed, using the centrifugal fractionation techniques. Well fed rats, fasted for 12 hours and non-treated were used. On the activity of UDPGGT, the glycogen fraction from the well fed rats was 11.45 and the final supernatant was 1.06. But the glycogen fraction from the fasted rats was 2.28 and the supernatant fluid was 2.25. According to these results, the activity of UDPGGT in the glycogen fraction from the well fed rats was higher than the other, while the glycogen particles of well fed rat liver were abundantly demonstrated. On the other hand, the phosphorylase activity was also considerably high in glycogen fraction under the same condition, but it was considered from the results that the balance of both enzyme activities tended to the side of glycogen synthesis. Glycogen particles of the fasted one were less abundantly demonstrated, and the activity of UDPGGT as well as phosphorylase tended to increase relatively in the supernatant, and it was considered that the enzyme activities were released from glycogen particles. These enzyme activities had no relation to fractions of the endoplasmic reticulum and microsome which were recognized by electronmicroscope. The total activities of UDPGGT and phosphorylase were 1.76 and 2.19 respectively in $2 \%$ liver homogenate, 0.13 and 34.47 respectively in muscle homogenate. Therefore it was considered from the results that these activities were in the intracellular matrix, keeping the balance of synthesis and degradation of glycogen by request and giving differences in the glycogen particles. Spheroidal branching structure of the liver glycogen particles reported separately may presumably result from the synthetic mechanism of the enzyme activity. 


\title{
Effects of a Novel (Streptomyces) Hyaluronidase (Amano) Digestion upon Some Histochemical Staining Reactions of Tissue Mucopolysaccharides
}

\author{
Kazuyori YamadA \\ Department of Anatomy, Nagoya University School of Medicine, Nagoya
}

\begin{abstract}
Effects of a novel (Streptomyces) hyaluronidase (Amano Co., Ltd., Japan) digestion upon the alcian blue $(\mathrm{pH} 1.0)$, alcian blue $(\mathrm{pH} 2.5)$, periodic acid-Schiff (PAS) and alcian blue-PAS stainings of mucopolysaccharides have been studied in the aortae and tracheal and ear cartilages of the rat and rabbit. In comparison with this, effects of testicular hyaluronidase(Sigma Co., Ltd.; U. S. A) digestion upon the same stainings were also tested. The Streptomyces hyaluronidase digestion failed to alter the alcian blue $(\mathrm{pH} 1.0)$ stainability of all the tissues, but diminished notably the alcianophilia of the aortae and peripheral areas of the cartilages stained by alcian blue $(\mathrm{pH} 2.5)$ or alcian blue-PAS. In contrast, the testicular hyaluronidase digestion resulted in a conspicuous diminution of all the alcian blue reactions of the tissues. From these results, it is presumed that (1) hyaluronic acid is present in both the aortae and cartilages of the two animal species, (2) the Streptomyces hyaluronidase digestion appears to remove only hyaluronic acid from tissue sections and (3) the testicular hyaluronidase digestoin appears to remove sulfated mucosubstances in addition to hyaluronic acid from the tissues. Thus' the use of the Streptomyces hyaluronidase digestion seems to be a new promising means for identiffying hyaluronic acid histochemically.
\end{abstract}

\section{Electron Microscopic Demonstration of Mucosubstances in the Pulmonary Alveolus}

Takuji OHкura

Department of Anatomy, Iwate Medical College, Morioka

Pulmonary tissue samples were obtained from a frog, tortoise, quail and rat. The tissues were placed in $2 \%$ glutaraldehyde (phosphate or cacodylate buffer, $\mathrm{pH}$ 7.2) for further trimming. Staining with ruthenium red was performed by the method of Luft. The tissue blocks were also prepared according to a modified alcian blue staining method for electron microscopy.

Ruthenium-positive and alcianophil material appeared as a continuous coat on the surface of the alveolar epithelium; the thickness of the electron dense material, variable even in the same section, was usually $25-40 \mathrm{~nm}$. In the samples from the tortoise lung, ruthenium-positive fibrillar material was accumulated on the epithelial lining, and also electron-opaque particles of ruthenium red deposited in some lamellar structures within the alveolar cells. Pretreatment with GPG $\left(10^{-3} M\right)$ significantly reduced the intensity of the colloidal iron reaction (Wetzel) at the alveolar coat of the type I pulmonary cell of the rat; however, $\mathrm{CPC}\left(10^{-3} \mathrm{M}\right) \mathrm{did}$ not alter the appearance of the iron-positive lining of the type II cells. 


\title{
Histochemical OFservations on the Oogenesis in Sea Urchin
}

\author{
Yoichiro Takashima and Atsushi Ubukata \\ Department of Anatomy, Osaka University Medical School, Osaka
}

Sea urchin ovaries and mature eggs were fixed in 3\% glutaraldehyde, $10 \%$ formalin, Carnoy, Bodian or 1\% osmium tetroxide and embedded in Epon, methacrylate or paraffin. Block staining in phosphotungstic acid (PTA) and periodic acid- or chromic acid- silver methenamine technique were employed for electron microscopy; for light microscopy PAS, Best's carmine, Alcian blue and colloidal iron stainings were employed.

Nurse cells adjacent to growing oocyte contain three kinds of "giant granules" (A, B and C granules) in the cytoplasm filled with glycogen particles. The nurse cells retract as oogenesis proceeds and the giant granules are broken down and uptaken into growing oocyte as nutrient materials. B and C granules in nurse cells and yolk granules in oocytes and mature eggs were PAS positive (paraffin, methacrylate and Epon sections, LM) and intensely stained with PTA and periodic acid-silver methenamine (PA-silver), but not with chromic acid-silver methenamine (Chr.A-silver) (EM). Glycogen particles in the nurse cell cytoplasm and small parts of A granules were stained with Chr.A-silver. In forming yolk granules and cortical granules both PTA and PA-silver positive part and negative part are observed.

The distribution of polysaccharide components in yolk and cortical granules derived from "giant granules" were discussed.

\section{Histochemical Demonstration of Sialic Acid}

\author{
Syunta Hirose, Nobuhiro Murai, Masayuki Yasutomi, Ryotaro Yamada, \\ Zenji Imasa, A. K. A. Razzad and Dennosuke Jinnai \\ Department of Surgery, Osaka University Medical School, Osaka
}

Recently, behavior of the sialic acid in the various diseases have given interest, and the studies about it have been often reported. All those studies, however, have been performed biochemically, and not histochemically. As for a histochemical method, Carlo Ravetto's method to which orcinol reaction was applied has been the only one. But his method is incomplete, because specimens are severely damaged in his method, besides identifications of reaction matter and the method of counter stain are not considered.

Then we tried a method to which orcinol reaction was applied in the similar manner and which could be utilized well enough as a histochemical method. After experiments, in orcinol reaction by pure material, sialic acid, fructose and tryptophane showed a similar reaction. But fructose could be distinguished from the other two in the points of the coloration and its rapid fading time. And as compared with the reaction of tryptophane by Serra's method, this reaction was different in 
the respects of the influence of fixation and the position of the positive reaction in the specimen. So we could think this reaction was almost originated from sialic acid. As for counter stain, we succeeded in the counter stain by iron reaction, and we could establish it as a histochemical method for demonstration of sialic acid.

\title{
Light and Electron Microscopic Properties of Polyglucose Intracellularly Synthesized by Enzymes
}

Tadao Takeughi, Mitsuo Sasaki and Teruo Iwamasa

\section{Department of Pathology, Kumamoto University School of Medicine, Kumamoto}

Polyglucose synthesized from uridine diphosphate glucose (UDPG) by UDPGglycogen glucosyltransferase (UDPGGT) in tissue cells stained red brown or red purple with iodine, while polyglucose synthesized from glucose-1-phosphate by phosphorylase stained blue or purple with iodine. Each polyglucose was different in digestion by $\alpha$-amylase and $\beta$-amylase.

On the electron microscope, the UDPGGT-polyglucose was revealed in the form of beads which were composed of particles from the smaller, less dense particulates to the larger, denser ones as in native glycogen particles, and which were arranged in strings as rosaries. The phosphorylase-polyglucose was demonstrated in different form from the former, and it was less dense, amorphous or very finely granular in shape.

According to our new electron microscopic observation in a high magnification, native glycogen particles appeared in the form of spheroidal branching body similar to the ice crystall structure by negative staining, and it was considered from the physicochemical results obtained in the other experiments (J. Electr. Micr. 19 (4), $1970)$ that the spheroidal branching body of glycogen particles presumably revealed the branching structure of $\alpha-1,4-1,6$-linkage polysaccharide itself.

On the basis of these results, the form of polyglucose particles presumably depends on a non-physiological regulation of the activity of enzymes concerning glycogen metabolism prepared under the artificial condition.

\section{Electron-histochemistry of a Polyglucose Synthesis by Phosphorylase in Rabbit Small Intestine Smooth Muscle}

\author{
Mitsuo Sasaki and Tadao Takeuchi
}

\section{Department of Pathology, Kumamoto University School of Medicine, Kumamoto}

In the past several years, the authors had success on investigations on electronhistochemistry of intracellular polysaccharide synthesis in rat skeletal muscle, liver cells, ascites hepatoma and in rabbit skeletal muscle cells.

In the present study, electron-histochemistry of the same kind as these past experiments was examined in rabbit small intestine smooth muscle. 
In the routine histochemistry by use of fresh frozen sections, new polyglucose synthesized within the smooth muscle cells from glucose-1-phosphate by phosphorylase was observed to be stained faintly blue with iodine reaction by light microscopical examination. In electron microscopical appearances, it was amorphous to fine granular in shape. These granules were smaller in size and lower in density than those of native glycogen observed in the unincubated control muscles, and they were similar to polyglucose which had been produced in rat skeletal muscle in our past experiment of the same kind. These polyglucose areas were formed within cytoplasms, especially in perinuclear regions in no relation to various organelles. These granules were deposited completely in monoparticulate fashion without forming rosettes or any other special aggregates.

\title{
Comparative Studies of Glycolytic Enzyme Activities in the Arterial wall of Man and Animals
}

\author{
Masahiko Kobayashi Tomoe Kuroiwa and Fujio Numano
}

\section{The Third Division, Department of Internal Medicine, Tokyo Ika-Shika National University, Tokyo}

The activity of glycolytic enzymes in the arterial wall was studied in man, monkey, dog, rat, rabbit, chicken and rat.

Materials and Methods: Specimen of the aorta and femoral artery of all experimental animals were removed immediately after sacrifice and they were frozen with dry ice. Specimen of man was taken within $4 \mathrm{hr}$ after death.

The histoenzymatic activity of phosphorylase (PR), branching enzyme, uridin diphosphate glycogen glucose transferase (UDPGGT), hexokinase (HK), glucosephosphate isomerase (GPI), phosphofructokinase (PFK), glucose-6-phosphate (G-6-PDH), aldolase, lactic dehydrogenase (LDH) were pursuited. Results: The histoenzymatic activity of glycolytic enzymes tested was generally weaker in the endothelial cells than muscular layers in all animals, except HK, GPI, and PFK which were stronger in the endothelial cells than muscular lavers in man, rabbit and chicken.

The activity of all glycolytic enzymes in the endothelial cells was also stronger in man, rabbit and chicken than monkey, dog, cat and rat and it was generally quite weak in the latter group of animals, except LDH and PFK, which are relatively strong even in the latter group of animals. These facts show a peculier dissimilarity between man and monkey and a peculier similarity between man and rabbit and chicken in the metabolism of arterial wall. It should be noted that PR activity was certified in the endothelial cells of the aorta and especially of the femoral artery of man, rabbit and dog. In the endothelial cells of all animals, a weak activity of G-6-PDH and a strong one of LDH were recognized, but the activity of both branching enzyme and UDPGGT was too weak to be recognized distinctly.

In medial layers the histoenzymatic activity of all these enzymes was certified in man and all animals. The activity of PR, aldolase and LDH was especially strong in man, rabbit, and chicken showing again a peculier similarity between 
man and rabbit and chicken. The activity of HK, PGM, GPI and G-6-PDH was weak in every case except chicken. In the medial layer of all kind of animals and man branching enzyme was certified its rather strong activity, while UDPGGT showed a weak activity.

\title{
Histoenzymatic Analysis in the Aortic Wall of Rabbits at the Course of Cholesterol-Feeding and its Modefication by Estrogen or Pyridinol-carbamate Treatment
}

\author{
Fujio Numano, Kenichi Katsu, Mikio Takenobu, \\ Atsushi Sagara and Takio Shimamoto \\ The Third Division, Department of Internal Medicine, \\ Tokyo Ika-Shika National UniversityMedical School, Tokyo
}

Histoenzymatic changes in the aortic wall of rabbits at the course of cholesterol feeding and its modification by the treatment with pyridinolcarbamate and estrogen, were pursuited.

Materials and Methods: One hundred and forty healthy albino rabbits of 6 month of age were fed with $1 \%$ cholesterol containing diet and 40 rabbits with regular diet. These cholesterol fed rabbits were divided into 3 groups, which were treated each with potato starch as placebo, $30 \mathrm{mg} / \mathrm{kg}$ of pyridinolcarbamate and $1 \mathrm{mg} / \mathrm{kg}$ of diethylstilbestrol. Every 5 rabbits of each group were sacrified in 1, 2, 3, 5, 8, 10, 12 and 15th week of the experiment and the activity of glycolytic enzymes and hydrolytic enzymes in the aorta were studied using the blind technique in the evaluation.

Results: The activity of glycolytic enzyme was uniformly increased in all three groups kept on cholesterol diet as compared with rabbits without cholesterol feeding at the end of the first week. At the end of second week, the activity turned to decrease in animals received estrogen and at the end of third week, it turned also to decrease in animals received cholesterol-diect alone and the decrease was especially marked at the end of fifth week in both groups and thereafter the decreased level was maintained.

In animals received cholesterol-diet and pyridinolcarbamate, the activity of glycolytic enzymes was not reduced throughout the 15 weeks of the treatment. The activities of acid phosphatase, alkalin phosphatase, esterase and lipase exhibited an increase in all animals at the end of second week and the increase continued further and the most remarkable increase was noted in animals received 10-12 weeks of cholesterol-diet alone. In the animals received cholesterol-diet added with estrogen or pyridinolcarbamate the increase was smaller than that of animals received cholesterol-diet alone. In animals received estrogen and cholesterol, necrosis was observed in the media accompanied by a markedly increased activity of alkalin, phosphatase.

These results possibly suggest a presence of different mechanism in the mode of effect on the metabolism of aortic wall between pyridinolcarbamate and estrogen, which have been shown to exhibit a common, but histologically different, antiatherosclerotic effect. 